\title{
PRESENÇA DE E-BOOKS NOS ACERVOS DE BIBLIOTECAS UNIVERSITÁRIAS
}

\section{PRESENCIA DE E-BOOKS EN LAS COLECCIONES DE LAS BIBLIOTECAS UNIVERSITARIAS}

\author{
Gabriele Maris Pereira Fenerick* \\ Marcia Regina Silva** \\ leda Pelógia Martins Damian***
}

\begin{abstract}
RESUMO
Introdução: A configuração atual da biblioteca tem se modificado. O principal ponto de mudança relaciona-se a desmaterialização dos seus acervos, ou seja, a constituição de acervos digitais. Embora a presença de obras digitais nesses ambientes informacionais seja cada vez mais comum, ainda há questões a serem discutidas em relação à aquisição e acesso a esses recursos.

Objetivo: Analisar a presença de e-books nos acervos de bibliotecas universitárias nacionais e internacionais com intuito de levantar aspectos relacionados à aquisição e acesso a essas obras.

Metodologia: Trata-se de uma pesquisa exploratória e descritiva, que compreende revisão de literatura, análise dos sites de bibliotecas universitárias nacionais e internacionais, aplicação de questionários, enviados por e-mail, a bibliotecários responsáveis pelas bibliotecas das instituições pesquisadas.

Resultados: Os resultados demonstram fragilidades na forma de gestão e divulgação do acervo digital. Tal problemática impacta diretamente no desenvolvimento de coleções digitais, no acesso e na apropriação de informações.

Conclusões: Com usuários cada vez mais autossuficientes, é importante que os mesmos sejam envolvidos no processo de tomada de decisões relacionadas à seleção de e-books, bem como tenham conhecimento das obras que compõem o acervo das bibliotecas.
\end{abstract}

Palavras-chave: Acesso à informação. Bibliotecas digitais. Bibliotecas universitárias.

\footnotetext{
*Mestranda do Programa de Pós-graduação em Ciência, Tecnologia e Sociedade - PPGCTS, UFSCar. E-mail: gabi.pereira.maris@gmail.com

**Docente do Departamento de Educação, Informação e Comunicação. Faculdade de Filosofia, Ciências e Letras de Ribeirão Preto. Universidade de São Paulo. Docente do Programa de Pós Graduação em Ciência, Tecnologia e Sociedade da Universidade Federal de São Carlos. Email: marciabibli@yahoo.com.br

***Docente do Departamento de Educação, Informação e Comunicação. Faculdade de Filosofia, Ciências e Letras de Ribeirão Preto. Universidade de São Paulo. E-mail: iedapm@usp.br
}

Inf. Inf., Londrina, v. 21, n. 3, p. 185 - 206, set./dez., 2016. 


\section{INTRODUÇÃO}

A configuração atual da biblioteca tem se modificado e um dos pontos dessa mudança relaciona-se a desmaterialização dos seus acervos, ou seja, a constituição de acervos digitais. Embora a presença de obras digitais nesses ambientes informacionais seja cada vez mais comum, ainda há questões a serem discutidas no que concerne à aquisição e acesso a esses recursos.

Segundo Silva, Parreira e Castro Filho (2013), a presença de dispositivos digitais e de tecnologias móveis em bibliotecas, mesmo que indiretamente, está atrelada ao mercado editorial. Os modelos de aquisição de e-books ${ }^{1}$ disponíveis no mercado influenciam o desenvolvimento de acervos digitais e também o acesso e empréstimo dessas obras.

O acervo de e-books de bibliotecas universitárias públicas é formado por obras de acesso restrito à comunidade acadêmica e obras de acesso livre. As obras de acesso livre podem ser acessadas pelo público externo as instituições.

A incorporação de e-books nos acervos das bibliotecas pauta-se na disponibilidade e no custo dessas obras no mercado editorial, que geralmente são menores que as obras impressas e, principalmente, no atendimento de uma demanda informacional dos usuários que estão mais familiarizados com recursos tecnológicos sem fio como laptops, celulares, pagers, e-readers e tablets, que permitem acesso à internet e, por sua vez, a uma infinidade de conteúdos digitais.

O processo de desenvolvimento de coleções digitais esbarra-se, principalmente, no formato de aquisição imposto pelo mercado editorial, que se traduz, basicamente, na venda de "pacotes" fechados, ou seja, em uma lista de títulos previamente definidos. A compra de títulos individuais pelas bibliotecas não é vantajosa devido ao custo. Essa imposição contribui para a aquisição de títulos que, muitas vezes, não são de interesse do usuário. Além disso, em alguns casos, há obras dentre a listagem de títulos adquiridos, que não têm o

1 Neste trabalho o termo e-book foi utilizado como sinônimo de livro digital.

Inf. Inf., Londrina, v. 21, n. 3, p. 185 - 206, set./dez., 2016.

www.uel.br/revistas/informacao/ 
Gabriele Maris Pereira Fenerick. Marcia Regina Silva. leda Pelógia Martins Damian. Presença de e-books nos acervos de bibliotecas universitárias

acesso liberado, o que exige atenção do bibliotecário ao contrato assinado com as editoras. Essa situação pode causar frustrações aos usuários, que não conseguem ter acesso ao conteúdo do título almejado. Outra questão relevante é que nesse modelo dificilmente se faz o acompanhamento estatístico de acesso às obras, o que restringe a elaboração de indicadores importantes para a tomada de decisão a respeito da continuidade da assinatura.

Com base no exposto, o objetivo desse trabalho é analisar a presença de e-books nos acervos de bibliotecas universitárias nacionais e internacionais com intuito de levantar aspectos relacionados à aquisição e à divulgação dessas obras. Para tal, além da análise dos sites dessas bibliotecas, foram aplicados questionários, enviados por e-mail aos bibliotecários responsáveis pelas bibliotecas das instituições pesquisadas.

\section{REFERENCIAL TEÓRICO}

Visto como um veículo de informação, o livro impresso registra há séculos a evolução das sociedades. Este suporte se tornou indispensável para o desenvolvimento informacional, além de ter adquirido grande representatividade enquanto elemento de preservação cultural, porém, seu domínio tem sido contestado devido à incorporação das Tecnologias de Informação e da Comunicação (TIC's).

Dentre essas tecnologias encontram-se o e-book, termo que se refere aos documentos digitais em formato de livro. O livro digital pode ser lido tanto pela internet como por compactos aparelhos eletrônicos, como celulares, ereaders e/ou tablets. Estes equipamentos têm como principais características possuir interface digital, dispondo de aplicativos que permitem uma personalização da leitura, adequando-se as necessidades pessoais do leitor, além da facilidade e agilidade no manuseio, e grande capacidade de armazenamento.

A atração exercida pela tecnologia pode ser favorável ao hábito de leitura, o que configura aceitação maior destes indivíduos mediante aos 
Gabriele Maris Pereira Fenerick. Marcia Regina Silva. Ieda Pelógia Martins Damian. Presença de e-books nos acervos de bibliotecas universitárias

produtos e serviços digitais disponibilizados em bibliotecas. Porém, existe uma polêmica sobre a utilização do e-book em razão da mudança que proporciona na forma de leitura: essa tentativa de maior interoperabilidade entre as informações pode gerar uma poluição tanto visual quanto informacional, resultando em prejuízos na concentração e na interpretação do usuário (DZIEKANIAK et al., 2010).

No entanto, não há como negar que o surgimento do livro eletrônico possibilitou maior interação entre o usuário e o conteúdo no que se refere ao acesso a obras internacionais ou obras raras que somente poderiam ser acessados in loco. O acesso a obra digital é vantajoso no sentido de não gerar danos à obra original impressa e, ainda, pode ser acessado por um maior número de pessoas ao mesmo tempo.

No Brasil, paira-se uma questão que se contrapõe ao crescimento do mercado editorial de e-books: grande parcela da população não esta adaptada e/ou familiarizada a esta tecnologia, além disso, o custo da internet e dos recursos tecnológicos ainda é um impedimento para a popularização. Por não possuirmos uma lei específica para obras digitais, há também falta de apoio legal em relação aos direitos autorais. No que se refere à reprodução de obras literárias, o Brasil baseia-se na Lei n 9.610, de 19 de fevereiro de 1998, que dispõe nos Artigos $5^{\circ}$ e $6^{\circ}$ o seguinte:

para os efeitos desta Lei, considera-se: VI - reprodução - a cópia de um ou vários exemplares de uma obra literária, artística ou científica ou de um fonograma, de qualquer forma tangível, incluindo qualquer armazenamento permanente ou temporário por meios eletrônicos ou qualquer outro meio de fixação que venha a ser desenvolvido; Não serão de domínio da União, dos Estados, do Distrito Federal ou dos Municípios as obras por eles simplesmente subvencionadas. (BRASIL, Lei 9.610/98, de 19 de fevereiro de 1998).

A fragilidade desta Lei em relação aos direitos autorais também dificulta a elaboração de políticas de empréstimos digitais de e-books. O Brasil ainda não conta com leis específicas para este serviço. Questões como a duração do empréstimo digital, opções de compartilhamento, restrições de acesso, entre outros, ainda são pontos a serem definidos. A falta de uma legislação 
Gabriele Maris Pereira Fenerick. Marcia Regina Silva. leda Pelógia Martins Damian. Presença de e-books nos acervos de bibliotecas universitárias

específica gera debates sobre o assunto, as editoras se sentem receosas devido à ameaça de pirataria e à queda das vendas e acabam criando condições que dificultam a aquisição de e-books para empréstimos nas bibliotecas.

A biblioteca digital democrática, de acesso irrestrito, ainda terá um grande caminho a percorrer, tanto em relação às questões institucionais como em relação às publicações disponibilizadas para o acesso mútuo a informação. Em relação ao bibliotecário, o mesmo encontra-se em um contexto diferente do que era considerado habitual: hoje se tornou um gestor e um implementador de informações, o que exige atualização constante para oferecer um atendimento eficiente e coerente com a realidade.

Na visão de Serra (2013), é possível visualizar uma mudança na forma como o usuário consome a informação, devido à diversidade de formatos e aos suportes disponíveis no mercado. O e-book e a internet permitem que as paredes das bibliotecas sejam derrubadas no que se refere ao acesso à informação.

Há outras vantagens que podem ser levantadas sobre os e-books: capacidade de armazenamento; por serem disponibilizados em plataformas próprias ou de terceiros, os livros eletrônicos também podem ser acessados por vários usuários ao mesmo tempo e; não precisam ser retirados na biblioteca física. Por outro lado, ainda há dúvidas quanto à segurança digital dessas obras. Há também questionamentos quanto à consolidada sensação de pertencimento do acervo, já que no modelo de aquisição por assinatura, por exemplo, à falta de pagamento significará o cancelamento do acesso. Neste caso, as obras não pertencem à biblioteca, estarão disponibilizadas apenas por um período determinado de tempo.

Silva (2013, p.10) reforça o que foi exposto,

essa forma de disponibilização de conteúdos permite ultrapassar os limites espaciais das bibliotecas físicas. O crescimento das coleções tradicionais cria custos como espaço físico para acomodação, com preservação de material, com perdas e extravios; problema que é minimizado pelas coleções digitais. Além disso, as bases podem ser acessadas remotamente, garantindo aos usuários de uma rede de 
bibliotecas, com unidades em locais distantes, o acesso igualitário a todos os recursos do sistema.

Quanto ao mercado digital, foram criados diferentes modelos de negociação entre empresas que comercializam e-books com as bibliotecas. Sheehan (2013) destaca uma série de investimentos e responsabilidades adicionais que essas instituições devem fazer, como: manter seu próprio servidor para armazenar os arquivos; manutenção do sistema de consulta e circulação; ter pessoal qualificado para garantir que o acesso ao material eletrônico seja respeitado de acordo com os direitos autorais e digitais de cada uma das obras adquiridas e; oferecimento de plataformas que atendam a todos os formatos dos livros eletrônicos disponíveis.

Dentre os modelos de negócios para a aquisição de livros eletrônicos, destacam-se a aquisição orientada pelo usuário, a assinatura, a aquisição perpétua e o empréstimo em curto prazo.

A aquisição orientada pelo usuário, mais conhecida como PDA (Patron Driven Acquisition), relaciona-se aos livros eletrônicos que são mais requisitados na unidade de informação, através da disponibilização do catálogo dos e-books para os usuários.

O modelo de assinatura apresenta coleções organizadas por assunto, onde a biblioteca pode adquirir o acesso a cada uma delas em específico. A bibliografia das coleções é pré-estabelecida pelo fornecedor, porém, depois de um determinado período de tempo outros títulos podem ser adicionados ou trocados, dependendo do tipo contratual, sendo renovada a assinatura anualmente (POLANKA, 2010).

Já na aquisição perpétua, o livro eletrônico passa a ser propriedade da biblioteca mediante pagamento de taxa anual, além do custo da obra, para manutenção da plataforma. O acesso é feito através da plataforma do fornecedor, porém, caso a biblioteca decida interromper o uso da plataforma, o fornecedor é obrigado a fornecer uma cópia do conteúdo em outro formato digital, como um CD-ROM.

O Pay-per-view, também chamado de empréstimo a curto prazo, segundo Grigson (2009), é quando o usuário tem aceso a um catálogo de livros 
Gabriele Maris Pereira Fenerick. Marcia Regina Silva. leda Pelógia Martins Damian. Presença de e-books nos acervos de bibliotecas universitárias

que não estão disponíveis no banco de dados da biblioteca e, caso ele solicite o empréstimo de alguns destes, a unidade de informação paga o valor da taxa para empréstimos e o e-book é liberado por um período predeterminado.

Serra (2013) afirma que o primeiro passo para o empréstimo de e-books em bibliotecas é o estabelecimento de uma política específica para livros eletrônicos que deve contemplar a quantidade de obras que podem ser utilizadas simultaneamente e o período de uso, fatores alinhados com o perfil do usuário. A maioria das bibliotecas realiza este trabalho por meio de nomes de usuário e senha. Uma vez identificado no histórico do usuário que não constam restrições, o empréstimo passa a ser realizado através do OPAC (Online Public Access Catalog) da biblioteca. A partir desta tecnologia é possível realizar o download do arquivo em seu dispositivo, com acesso/consulta com durabilidade do empréstimo preestabelecido na política da unidade de informação, não sendo necessário o uso de internet. Após o período de empréstimo, o arquivo apaga-se automaticamente do dispositivo.

De acordo com Brayner (2011, p.10), os principais problemas na busca por conteúdos eletrônicos disponíveis em bibliotecas são:

- catálogos eletrônicos apresentam títulos de coleções (ex: Early english Books Online) ao invés de títulos individuais, o que dificulta a localização e a consulta de livros em formato digital;

- inconsistência nos metadados que são gerados por editoras;

- interatividade entre catálogos e links de acesso a conteúdos eletrônicos se apresentam, muitas vezes, de forma desorganizada, o que gera problemas de navegação e consulta;

- plataformas sem opções de "buscas federadas" (Federated Search) que poderia possibilitar a pesquisa simultânea em vários motores de busca;

- ausência de "exibição personalizada" de resultados com dicas de materiais para consulta. 
Cabe à biblioteca facilitar o acesso e o empréstimo de livros eletrônicos disponíveis em suas bases de dados, porém, elas enfrentam um grande desafio na transição entre o tradicional e o digital que acarreta alterações e adaptações na gestão informacional destas unidades de informação. É importante então, o estabelecimento de um modelo de negócio que satisfaça às necessidades e os anseios de todos os agentes envolvidos no processo, isto é, autores, editores, bibliotecários e usuários.

Em 2012, a American Library Association (ALA) lançou um relatório na American Library Magazine intitulado "E-book business models for public libraries", demonstrando a preocupação das bibliotecas em se adequarem ao atual cenário dos e-books. O relatório descreve as características gerais e os atributos do ambiente atual do e-book, as restrições de modelos de negócios atuais e sugere oportunidades para as editoras mostrarem conteúdo por meio de bibliotecas públicas. Além disso, o Relatório da ALA (2012, p. 3, tradução nossa) recomenda três atributos básicos que devem ser encontrados em qualquer modelo de negócio para e-books:

- Inclusão de todos os títulos - Todos os títulos de ebooks disponíveis para venda ao público também devem estar disponíveis para o empréstimo em bibliotecas. As bibliotecas podem optar por não comprar alguns títulos se as restrições ou os preços forem considerados inaceitáveis, mas reter títulos sob quaisquer termos remove a capacidade da biblioteca para fornecer os serviços de seus clientes precisam e esperam.

- Direitos duradouros - As bibliotecas devem ter uma opção de efetivamente possuir os e-books que comprarem, incluindo o direito de transferi-los para outra plataforma e de continuar a emprestá-los indefinidamente. As bibliotecas podem escolher opções mais limitadas para alguns títulos ou cópias em troca de preços mais baixos, 
mas eles devem ter alguma opção que permita o acesso duradouro permanente.

- Integração - Bibliotecas devem tentar fornecer acesso coerente entre todos os serviços por eles oferecidos. Para fazer isso de forma eficaz, eles precisam de acesso aos metadados e ferramentas de gestão fornecidas pelos editores ou distribuidores para melhorar a descoberta de e-books. Ofertas autônomas separadas dos e-books poderão ficar à margem ou para diminuir a consciência de outras ofertas da biblioteca. Mecanismos que permitam a descoberta de e-books através do catálogo da biblioteca, o acesso e a reserva remota sem complexidade são necessidades básicas.

De acordo com Serra (2012), a venda de e-books para bibliotecas têmse destacado pelo fato de que as editoras estabelecem políticas diferenciadas para aquisição, chegando, inclusive, a cobrar ate três vezes mais pelo preço de suas obras. Como justificativa alegam que em bibliotecas a circulação é ilimitada e perpétua, o que pode prejudicar seu capital.

Contudo, Silva (2013) afirma que levando em conta a realidade brasileira, há ainda outro fator que interfere na aquisição de e-books por bibliotecas: a exclusão social (e digital) de um número significativo pessoas que ainda não têm acesso aos acervos tradicionais. Esta exclusão limita o acesso pleno da população às novas tecnologias de leitura e, infelizmente, não é um novo formato de livros que mudará essa situação.

Com as mudanças nas relações de aquisição de conteúdo e sua disponibilização ao usuário, é necessário repensar o desenvolvimento de coleções, de forma a garantir a continuidade de títulos nos acervos, mensurar o uso que é feito das obras adquiridas, aferir o controle de acesso aos conteúdos para evitar utilizações não autorizadas, além de oferecer novas possibilidades de consultas e serviços.

Acrescenta-se a estes fatos as questões ligadas à necessidade da 
Gabriele Maris Pereira Fenerick. Marcia Regina Silva. Ieda Pelógia Martins Damian. Presença de e-books nos acervos de bibliotecas universitárias

criação de uma legislação para bibliotecas no que diz respeito à propriedade na aquisição dos livros eletrônicos, seja qual for à forma de aquisição. Porém, é visível que o Brasil não é o único país com esta necessidade. Apesar de outros avanços, países desenvolvidos, como os Estados Unidos, ainda demonstram adaptação a este novo suporte e, cabe ao bibliotecário conhecer e analisar essas problemáticas como forma de participarem das decisões sobre os rumos da circulação de obras digitais em bibliotecas universitárias.

Para Cunha (2010), nem todas as bibliotecas universitárias se transformarão em bibliotecas digitais. Entretanto, elas continuarão a oferecerem um acervo híbrido que corresponderá às necessidades dos grupos de usuários. As bibliotecas precisam se responsabilizar pelo gerenciamento do seu acervo que pode ter sido comprado, alugado, arrendado ou assinado, caso contrário, correm o risco de serem substituídas por empresas comerciais provedoras de informação.

Segundo Silva (2013, p. 2),

no Brasil, muitas bibliotecas de instituições públicas e privadas mantêm algum tipo de coleção digital. Algumas dessas coleções são abertas a qualquer usuário e/ou possuem materiais de acesso livre; outras são restritas aos usuários ligados à sua instituição mantenedora. Dentre as coleções digitais brasileiras com materiais sem restrição de acesso pode-se destacar a Biblioteca Brasiliana USP, o portal Domínio Público e as bibliotecas de teses e dissertações de universidades públicas. Os usuários destas coleções podem descarregar os itens em seus próprios equipamentos ou ler diretamente na web.

Para a formação de coleções digitais, as bibliotecas procuram títulos indicados por usuários e/ou selecionam documentos isentos de direitos autorais ou mesmo digitalizam obras importantes do seu acervo impresso. Isto tem sido feito principalmente com obras raras e manuscritos, e, após a existência do documento digital, a preservação do original poderá ser feita a custos menores e com possibilidade de ampliar sua disponibilidade. Essas ações demonstram que muitas bibliotecas continuarão a prover novas e especializadas coleções construídas de acordo com políticas de desenvolvimento de coleções bem definidas (CUNHA, 1999, p.7). 


\section{METODOLOGIA}

Para a condução do estudo, foi definido um deliamento de pesquisa qualitativo. Essa pesquisa é de natureza básica, seu objetivo é analisar a presença de e-books nos acervos de bibliotecas universitárias nacionais e internacionais com intuito de levantar aspectos relacionados à aquisição e acesso a essas obras. Quanto à forma de abordagem, trata-se de uma pesquisa exploratória e descritiva, desenvolvida em duas fases:

1. revisão de literatura: foram utilizadas para o levantamento bibliográfico questões a respeito da temática: e-books e bibliotecas universitárias. Tal levantamento foi realizado nas seguintes bases de dados nacionais e internacionais: Library and Information Science Abstracts (LISA) da ProQuest, Information Science \& Technology Abstracts (ISTA) e Library, Information Science \& Technology da EBSCO, SCOPUS da Elsevier e Scielo.

\section{2. análise dos catálogos de e-books disponibilizados por bibliotecas nacionais e internacionais:}

- Bibliotecas nacionais: foi realizado um levantamento que permitiu eleger bibliotecas de IES (Instituições de Ensino Superior) públicas da região sudeste brasileira, são elas: Universidade Federal do Rio de Janeiro (UFRJ), Universidade Federal de Uberlândia (UFU), Universidade Federal do Espírito Santo (UFES), Universidade Estadual Paulista (UNESP), Universidade Estadual de Campinas (UNICAMP) e Universidade de São Paulo (USP). O Estado de São Paulo encontra-se representado por três universidades que possuem grande representatividade no Brasil, já a UFRJ, UFU e UFES foram escolhidas devido à melhor disponibilização dos dados nos sites. Foram coletadas nos sites dessas bibliotecas universitárias informações a respeito da forma de aquisição e divulgação de ebooks.

- Bibliotecas internacionais: foram eleitas bibliotecas de universidades americanas e europeias, são elas: Universidade de 
Coimbra, Portugal, Universidade Yale, Estados Unidos, Universidade de Salamanca, Espanha, Universidade de Dublin, Irlanda, Universidade de Cambridge, Reino Unido e a Universidade de Johns Hopkins, Estados Unidos. A escolha dessas universidades também se baseou na maior disponibilidade de dados nos sites.

Ainda no que se refere à segunda fase, para complementação das informações obtidas nos sites das bibliotecas, foi enviado, por e-mail, um questionário intitulado "Incorporação de e-books em bibliotecas universitárias". A mesma versão em inglês foi enviada as instituições internacionais. Das doze instituições (nacionais e internacionais), apenas cinco bibliotecários, responsáveis pelas bibliotecas, se dispuseram a participar da pesquisa, sendo três bibliotecários de instituições nacionais e duas de instituições internacionais. Os e-mails foram enviados aos bibliotecários em setembro de 2014 e reenviados em outubro do mesmo ano. No dia 03 de dezembro de 2014, prazo estipulado para encerramento da coleta de dados, cinco bibliotecários haviam respondido os e-mails, com apresentação do questionário respondido. Os outros sete bibliotecários não se manifestaram quanto ao recebimento do e-mail e participação na pesquisa.

O questionário foi constituído de questões que visaram identificar a existência de dados estatísticos relacionados ao empréstimo de e-books realizado pelas bibliotecas, a principal forma de aquisição de e-books adotada pela biblioteca, o oferecimento de tecnologias móveis para a leitura de e-books (tablets, e-readers, etc.), dados que comprovem se a aquisição de e-books diminuiu a aquisição de obras impressas e, dados sobre o custo da aquisição de e-books em relação à aquisição de obras impressas.

Os dados obtidos com o levantamento nos sites das bibliotecas e com as respostas dos questionários foram estruturados e serão apresentados a seguir. Ressalta-se, porém, que por não ser uma pesquisa quantitativa, optouse por não enfatizar em todos os dados o nome das Instituições. A intenção é ter uma ideia genérica que possa contribuir no desenvolvimento de pesquisas posteriores. 


\section{FORMAS DE AQUISIÇÃO E DIVULGAÇÃO DE E-BOOKS EM BIBLIOTECAS UNIVERSITÁRIAS}

A coleta de dados nos sites das bibliotecas universitárias visou levantar informações sobre a quantidade de títulos de e-books disponíveis nas bibliotecas, as principais editoras, o modelo de aquisição adotado e forma de acesso aos e-books.

Em relação à quantidade de títulos de e-books que compõem o acervo das IES públicas nacionais, verificou-se que nem todas as bibliotecas disponibilizam essa informação nos sites. Das universidades selecionadas apenas os sites das bibliotecas da UFU, UNICAMP, UNESP e USP divulgam a quantidade de e-books disponíveis, demonstrados na tabela um.

Tabela 1 - Quantidade de títulos de e-books disponíveis por universidade

\begin{tabular}{|l|cc|}
\hline Biblioteca & $\begin{array}{l}\text { Quantidade } \\
\text { disponíveis }\end{array}$ & títulos de e-books \\
\hline UFU & 4.113 \\
\hline UNICAMP & 451.529 \\
\hline UNESP & 65.000 \\
\hline USP & 182.000 \\
\hline TOTAL & 702.642 \\
\hline
\end{tabular}

Fonte: Elaboração das autoras

Podemos perceber que, somente no Estado de São Paulo, há mais de 698.500 títulos de e-books disponíveis nas principais universidades públicas pesquisadas. Os estudantes universitários têm a disposição uma quantidade importante de títulos que podem ser acessados no formato digital. Tais universidades disponibilizam geralmente o acesso remoto VPN (Virtual Private Network), o que significa que é possível acessar tais obras fora do ambiente da biblioteca.

Apenas uma instituição não disponibiliza no site informações a respeito das editoras que mantêm contratos. As outras cinco bibliotecas comercializam e-books com editoras que têm representatividade nas diversas áreas do conhecimento, são elas: Atheneu, Springer, Ebscohost, IEEE/IET Electronic 
Gabriele Maris Pereira Fenerick. Marcia Regina Silva. leda Pelógia Martins Damian. Presença de e-books nos acervos de bibliotecas universitárias

Library (IEL), Editoras Wiley e Cambridge, CRCnetBASE, e-books Lippincott Williams \& Wilkins(LWW), E-brary, E-livro, ECCO, Energy \& Environmental Sciences MOMW - The Making of the Modern World, NetLibrary, Referex, Safari, Biblioteca Virtual 3.0 da Pearson,BioOne, Books from the Past, Classifiques Sciences Sociales, DOAB Directory of Open Access Books, Elsevier Health, Free E-Journals, Galegroup, Gallica, Gutenberg-e, Hein Online, Historical Jewish Press, In Tech Books, Knovel, Lexis Nexis, Making of America (Cornell), McGraw Hill Acess, Miscellaneous Free Books, National Academies Press, NeLibrary Publicity Accessible eBooks, OAPEN, OECD ILibrary, OpenEdition Books, Pe'er, Persee, PoPuPS, Project Euclid, ProQuest New Platform, Psychoanalytic Eletronic Publishing, Retrodigitized Journals (SEALS), Terrapub Books, University of California Press e US Government Documents.

Em relação ao tipo de modelo de aquisição adotado pelas bibliotecas, verificou-se que quatro bibliotecas adotam o modelo de "distribuidores e agregadores por assinatura", uma biblioteca adota o modelo de "aquisição perpétua através de editoras" e uma biblioteca não informa o modelo adotado no site.

No quadro um tem-se uma avaliação a respeito da disposição dos ebooks nos sites das bibliotecas.

Quadro 1 - Presença de e-books nos sites de bibliotecas universitárias brasileiras

\begin{tabular}{|c|l|}
\hline BIBLIOTECA & \multicolumn{1}{|c|}{ DISPONIBILIZAÇÃO DOS E-BOOKS NOS SITES } \\
\hline UFRJ & $\begin{array}{l}\text { Há um link para acesso as editoras de livros eletrônicos } \\
\text { assinados pelo SiBI (Sistema de Bibliotecas) da UFRJ. As obras } \\
\text { eletrônicas assinadas não constam nos catálogos das bibliotecas } \\
\text { do Sistema. }\end{array}$ \\
\hline UFU & $\begin{array}{l}\text { Há divulgação no site do SISBI - Sistemas de Bibliotecas- da } \\
\text { UFU. É importante ressaltar que o site do SISBI apresenta fácil }\end{array}$ \\
\hline
\end{tabular}


Gabriele Maris Pereira Fenerick. Marcia Regina Silva. leda Pelógia Martins Damian. Presença de e-books nos acervos de bibliotecas universitárias

\begin{tabular}{|c|c|}
\hline & $\begin{array}{l}\text { acesso aos e-books. As obras eletrônicas assinadas não } \\
\text { constam nos catálogos das bibliotecas do Sistema. }\end{array}$ \\
\hline UFES & Há links com acesso a listagem de títulos assinados. \\
\hline UNICAMP & $\begin{array}{l}\text { O acesso aos e-books é feito por meio do Portal de Acesso à } \\
\text { Informação Eletrônica (PAl-e). É possível localizar os e-books por } \\
\text { meio do índice de títulos ou categoria de assuntos, porém, o } \\
\text { acesso ao PAl-e não é intuitivo no site das Bibliotecas. }\end{array}$ \\
\hline UNESP & $\begin{array}{l}\text { Há boa divulgação e esclarecimento sobre as áreas em que cada } \\
\text { plataforma direciona. }\end{array}$ \\
\hline USP & $\begin{array}{l}\text { O acesso à coleção de livros eletrônicos (e-books) dá-se por } \\
\text { meio do acesso ao Portal de Busca Integrada onde há um link } \\
\text { para Livros Eletrônicos (e-books). }\end{array}$ \\
\hline
\end{tabular}

Fonte: Elaboração das autoras

A experiência com a coleta das informações que compõem o quadro um demonstra que o acesso aos e-books nos sites das bibliotecas não é intuitivo. Para chegar à listagem das obras assinadas é preciso acessar o site dos Sistemas de Bibliotecas e não diretamente o site das bibliotecas. Os links para acesso aos e-books das diferentes bibliotecas utilizam os termos: E-books/EJornals/ Buscadores; Livros Eletrônicos (e-books); e-Revistas/Livros; Livros Eletrônicos e; Serviços e Pesquisa. Tais links dão acesso às editoras. Para ter acesso aos títulos é preciso acessar as editoras individualmente. Em relação a este aspecto, destaca-se a experiência da UNICAMP que possui um Portal de Acesso à Informação Eletrônica (PAI-e) no qual é possível localizar os e-books por meio do índice de títulos ou categoria de assuntos.

Entende-se que essas universidades são responsáveis pela disponibilização de informação científica e contribuem diretamente no desenvolvimento da pesquisa brasileira, devem então, preocuparem-se com o incentivo ao acesso do seu acervo digital.

Nota-se que todas as bibliotecas assinam coleções de e-books de 
Gabriele Maris Pereira Fenerick. Marcia Regina Silva. leda Pelógia Martins Damian. Presença de e-books nos acervos de bibliotecas universitárias

importantes editoras, porém, justamente pelo padrão de aquisição ser a assinatura, os títulos não constam nos catálogos das bibliotecas. O acesso é realizado por meio de links que direcionam para as editoras. Apenas a UFU adota o modelo de aquisição perpétua, o que significa que alguns e-books podem pertencer ao acervo das bibliotecas.

Embora a totalidade das universidades públicas brasileiras não esteja representada neste estudo, os resultados ora apresentados denotam a necessidade latente das bibliotecas elaborarem políticas de acesso e de gestão dessas coleções digitais. Há pouca divulgação dos títulos de e-books assinados. Essa situação impede que esse acervo seja de conhecimento da comunidade acadêmica, e a questão ainda mais problemática é a falta de controle em relação ao acesso, não há estatísticas de uso, o que impede a tomada de decisões em relação aos títulos que devem permanecer no acervo. O investimento nesses recursos é alto, justificando a necessidade de sensibilização das comunidades acadêmicas para o uso desse material.

Visando delinear a situação do acervo de e-books das bibliotecas estrangeiras, apresenta-se no quadro dois uma avaliação a respeito da disposição dos e-books nos sites das bibliotecas estrangeiras.

Quadro 2 - Presença de e-books nos acervos de bibliotecas universitárias estrangeiras

\begin{tabular}{|l|l|}
\hline \multicolumn{1}{|c|}{ BIBLIOTECA } & \multicolumn{1}{|c|}{ ACESSO } \\
\hline $\begin{array}{l}\text { Universidade de } \\
\text { Coimbra }\end{array}$ & $\begin{array}{l}\text { O link para acesso aos livros eletrônicos encontra-se no site } \\
\text { do Serviço Integrado das Bibliotecas da Universidade de } \\
\text { Coimbra. Não há assinatura de editoras específicas, apenas } \\
\text { disponibilização de e-books de acesso gratuito. }\end{array}$ \\
\hline $\begin{array}{l}\text { Universidade } \\
\text { Yale }\end{array}$ & $\begin{array}{l}\text { A universidade disponibiliza um site específico para este tipo } \\
\text { de suporte, porém, o acesso não é intuitivo, o usuário precisa } \\
\text { percorrer todo o site para encontrar a listagem de títulos de e- } \\
\text { books. }\end{array}$ \\
\hline
\end{tabular}


Gabriele Maris Pereira Fenerick. Marcia Regina Silva. leda Pelógia Martins Damian. Presença de e-books nos acervos de bibliotecas universitárias

\begin{tabular}{|l|l|}
\hline $\begin{array}{l}\text { Universidade de } \\
\text { Salamanca }\end{array}$ & $\begin{array}{l}\text { Divulgação de publicações digitais no site da rede de } \\
\text { bibliotecas da universidade; facilidade no manuseio de suas } \\
\text { ferramentas. }\end{array}$ \\
\hline $\begin{array}{l}\text { Universidade de } \\
\text { Dublin }\end{array}$ & $\begin{array}{l}\text { Divulgação de publicações digitais disponibilizadas pela } \\
\text { instituição no site da biblioteca. Acesso é realizado por meio } \\
\text { do catálogo da biblioteca. }\end{array}$ \\
\hline $\begin{array}{l}\text { Universidade de } \\
\text { Cambridge }\end{array}$ & $\begin{array}{l}\text { Divulgação de publicações digitais disponibilizadas pela } \\
\text { instituição no site da biblioteca; facilidade no manuseio de } \\
\text { suas ferramentas. }\end{array}$ \\
\hline $\begin{array}{l}\text { Universidade de } \\
\text { Johns Hopkins }\end{array}$ & $\begin{array}{l}\text { O acesso não é intuitivo, o usuário precisa percorrer todo o } \\
\text { site para encontrar a listagem de títulos de e-books. }\end{array}$ \\
\hline
\end{tabular}

Fonte: Elaboração das autoras

As bibliotecas nas IES estrangeiras não disponibilizam muitas informações a respeito do acervo de e-books. Nenhuma biblioteca informa a editora a qual mantém contrato. Apenas duas bibliotecas disponibilizam em seus sites informações sobre a quantidade de títulos de e-books disponíveis (Universidade de Dublin, 8.000 títulos; Universidade de Cambridge, 17.504 títulos). Mas observa-se que o número de títulos disponibilizado é bem inferior à média das bibliotecas nacionais que fizeram parte desta pesquisa. Três bibliotecas disponibilizam nos sites informações sobre o modelo de aquisição adotado (Universidade Yale, Distribuidores e agregadores por aquisição orientada pelo usuário; Universidade de Salamanca, Distribuidores e agregadores por seleção e; Universidade de Dublin, Distribuidores e agregadores por assinatura). No entanto, aparece entre os resultados o modelo de aquisição voltado ao usuário e por seleção, tais modelos podem ser mais efetivos por aproximarem das necessidades informacionais dos usuários.

No que concerne à forma de acesso aos e-books nos sites das bibliotecas estrangeiras, constatou-se acesso mais rápido a listagem de títulos em relação às bibliotecas brasileiras. O acesso aos e-books da Universidade 
Gabriele Maris Pereira Fenerick. Marcia Regina Silva. leda Pelógia Martins Damian. Presença de e-books nos acervos de bibliotecas universitárias

de Dublin, por exemplo, dá-se por meio do próprio catálogo do acervo da instituição. Ao fazer a busca no catálogo é possível recuperar obras impressas e digitais. Porém, a falta de informações e a dificuldade de acesso à listagem de títulos dos e-books, disponíveis pelas bibliotecas, demonstra certa fragilidade no que se refere à aproximação entre usuário e biblioteca²

Em relação às respostas obtidas com a aplicação dos questionários (nacional e internacional), verificou-se que as bibliotecas possuem em seus acervos obras digitais, porém, ainda não há controle estatístico específico sobre o empréstimo destas obras. Apesar disso, as respostas sugerem crescimento do serviço de empréstimo de e-book. Assim como observado nos sites, constatou-se nos questionários que as bibliotecas brasileiras utilizam o modelo de aquisição por assinatura em detrimento aos outros modelos existentes.

Quanto aos suportes disponibilizados aos usuários, as universidades têm computadores como principal suportee disponibilizam e-readers como segunda opção. Segundo os bibliotecários que responderam o questionário, na biblioteca universitária da UNESP e na biblioteca da Universidade de Salamanca houve diminuição no empréstimo de obras impressas a partir da aquisição de e-books. Nenhuma biblioteca deu informações que refutem ou confirmem que o investimento na aquisição de e-books é menor que o investimento na aquisição de obras impressas.

Os resultados apresentados demonstram a necessidade latente de melhor gestão e divulgação direcionada dos e-books presentes nos acervos das bibliotecas. Apesar da disponibilização e diversificação do conteúdo dos ebooks, entende-se que falta de padronização na política de aquisição e a falta de divulgação do acervo digital recai diretamente no acesso e apropriação da informação, prejudicando o desenvolvimento de pesquisas científicas.

\footnotetext{
2 Encontra-se em desenvolvimento pelas autoras deste trabalho uma pesquisa que visa obter informações sobre o conhecimento e a utilização desses recursos pelos usuários destas instituições.
}

Inf. Inf., Londrina, v. 21, n. 3, p. 185 - 206, set./dez., 2016. 


\section{CONCLUSÕES}

Em síntese, observou-se que ainda não há consenso sobre a forma de aquisição de e-books e também há pouca divulgação sobre os títulos de ebooks disponíveis nas bibliotecas. Tais problemáticas interferem diretamente no empréstimo digital de e-books. O empréstimo digital esbarra-se principalmente na falta de políticas definidas de direitos autorais que, por sua vez, aumenta o risco de pirataria.

O caminho para o desenvolvimento de bibliotecas híbridas ainda apresenta questões a serem discutidas e adaptadas ao contexto universitário. Ainda há bibliotecas atreladas a um modelo conceitual de gestão de acervos de natureza apenas físico, sendo importante que haja um reposicionamento do profissional da informação frente aos serviços e produtos oferecidos nas bibliotecas.

Os e-books enfrentam óbices que também foram enfrentados, de certa maneira, no surgimento dos livros impressos. O acesso à informação impressa e digital interfere diretamente nas questões políticas e sociais da sociedade, o que reforça a importância de estudos que visem associar temáticas importantes, como a curadoria digital e o processo de desenvolvimento e gestão de coleções digitais.

A partir do exposto, é possível afirmar que há fragilidades na forma de gestão e divulgação do acervo digital. Tal problemática impacta diretamente no desenvolvimento de coleções digitais. Com usuários cada vez mais autossuficientes, é importante que os mesmos sejam envolvidos no processo de tomada de decisões relacionadas à seleção de e-books que compõem o acervo das bibliotecas.

\section{REFERÊNCIAS}

AMERICAN LIBRARY ASSOCIATION. EBook business models for public libraries, 2012. Disponível em: <http://connect.ala.org/files/80755/EbookBusinessModelsPublicLibs.pdf>. Acesso em: 25 out. 2013. 
BRASIL. Lei n. ${ }^{\circ} 12.853$, de 19 de fevereiro de 1998. Presidência da República, Casa Civil, Subchefia para assuntos jurídicos, Brasília, 19 fev.1998. Artigo V/VI. Disponível em: <www.planalto.gov.br/ccivil_03/leis/l9610.htm>. Acesso em: 05 nov. 2013.

BRAYNER, A. A. Uso de ebooks em bibliotecas públicas e acadêmicas no Reino Unido. Londres, 2011. Disponível em: <http://pt.slideshare.net/Aquilesbrayner/ebooks-15206875>. Acesso em: 08 nov. 2013.

CUNHA, M. B. A biblioteca universitária na encruzilhada. DataGramaZero Revista de ciência da informação, [S.L], v. 11, n. 6, dez. 2. Disponível em: <http://www.datagramazero.org.br/dez10/Art_07.htm>. Acesso em: 13 dez. 2012.

CUNHA, M. B. Desafios na construção de uma biblioteca digital. Ciência da Informação, Brasília, v. 28, n. 3, p. 257-268, dez./12. 1999. Disponível em: <http://www.scielo.br/pdf/ci/v28n3/v28n3a3.pdf>. Acesso em: 20 jan. 2013.

DZIEKANIAK, G. V. et al. Considerações sobre o e-book: do hipertexto à preservação digital. Biblos: Revista do Instituto de Ciências Humanas e da Informação, [S.L], v. 1, n. 2, p. 83-99, jul./dez. 2010. Disponível em: <http://www.seer.furg.br/biblos/article/view/1899>. Acesso em: 13 dez. 2012.

GRIGSON, A. Evaluating business models for e-book through usage data analysis: a case study from de University of Westminster. Journal of Eletronic Resouces Librarianship, S/L, v. 21, n. 1, p. 62-74, 2009. Disponível em: <https://core.ac.uk/download/files/138/1927665.pdf>. Acesso em: 20 nov. 2013.

POLANKA, S. No shelf required: e-books in libraries. Chicago: American Library Association Editions, 2010.

SERRA, L. G. Bibliotecas do futuro e o foco no usuário. CRB-8 Digital, São Paulo, v. 6, n. 1, p. 11-19, ago. 2013. Disponível em: <http://revista.crb8.org.br/index.php/crb8digital>. Acesso em: 25 out. 2013.

SERRA, L. G. Empréstimo digital: como atender editores bibliotecas e usuários: estudo sobre novos modelos de negócios. In: Seminário Nacional de Bibliotecas Universitárias. 27., 2012, Gramado. Anais... Gramado, 2012. Disponível em: <http://www.snbu2012.com.br/anais/pdf/4Q2H.pdf> Acesso em: 25 out. 2013.

SHEEHAN, K. Ebook revolution: a primer for librarians on the front lines. Santa Barbara, CA, USA: ABC-CLIO, 2013. 
SILVA, M. R.; PARREIRA, D. E.; CASTRO FILHO, C. M. Incorporação de tecnologias digitais e dispositivos móveis em bibliotecas. In: ENCONTRO IBÉRICO EDICIC. 6., 2013, Porto. Anais...Porto: Faculdade de Letras da Universidade do Porto - CETACMEDIA, 2013. v. 6. p. 1250-1266.

SILVA, R. A. E-books em bibliotecas: novos desafios para os bibliotecários. In: CONGRESSO BRASILEIRO DE BIBLIOTECONOMIA, DOCUMENTO E CIÊNCIA DA INFORMAÇÃO. 25., 2013, Florianópolis. Anais... Florianópolis, 2013. Disponível em: <http://portal.febab.org.br/anais>. Acesso em: 08 nov. 2013.

\title{
Title
}

Presence of e-books in the collections of university libraries

\begin{abstract}
Introduction: The current library configuration has been modified. The main point of change relates to dematerialization of their collections, namely the creation of digital archives. Although the presence of e-books such information environments is increasingly common, there are still many issues to be discussed in relation to the acquisition and access to these resources.

Objective: To analyze the presence of e-books in the collections of international national university libraries and to raise issues related to the acquisition and dissemination of these works.

Methodology: This is a qualitative research with literature review, it analyzed of the websites of these libraries and it was applied questionnaires sent by e-mail to the responsible for the libraries of the institutions surveyed.

Results: The results show weaknesses in the way of management and dissemination of digital collections. These problems directly impact on the development of digital collections, access and ownership information.

Conclusions: With increasingly reliant users, it is important that they are involved in making decisions related to the selection of e-books, as well as they have knowledge of the works that make up the collection of libraries process.
\end{abstract}

Keywords: Information access. Digital libraries. Academic libraries.

\section{Titulo}

Presencia de e-books en las colecciones de las bibliotecas universitarias

\section{Resumen}

Introducción: La configuración actual de la biblioteca ha cambiado. El principal punto de cambio se refiere a la desmaterialización de sus colecciones, a saber, la creación de archivos digitales. Aunque la presencia de obras digitales tales entornos de información es cada vez más común, todavía hay muchas cuestiones que se debatirán en relación con la adquisición y el acceso a estos recursos.

Objetivo: Analizar la presencia de libros electrónicos en las colecciones de las bibliotecas universitarias nacionales e internacionales con el objetivo de plantear 
Gabriele Maris Pereira Fenerick. Marcia Regina Silva. leda Pelógia Martins Damian.

Presença de e-books nos acervos de bibliotecas universitárias

cuestiones relacionadas con la adquisición y el acceso a estas obras.

Metodología: Se trata de una investigación cualitativa que comprende revisión de la literatura, el análisis de los sitios de las bibliotecas universitarias nacionales e internacionales, cuestionarios enviados por correo electrónico, los bibliotecarios responsables de las bibliotecas de las instituciones encuestadas.

Resultados: Los resultados muestran deficiencias en la gestión y difusión de los activos digitales. Este problema tiene un impacto directo en el desarrollo de colecciones digitales, el acceso y la información de propiedad.

Conclusiones: Con los usuarios cada vez más independientes, es importante que estén involucrados en el proceso de toma de decisiones relacionadas con la selección de los libros electrónicos, así como tener conocimiento de las obras que componen la colección de bibliotecas.

Palabras clave: Acceso a la información. Bibliotecas electrónicas. Bibliotecas acadêmicas.

Recebido em: 10.04.2016

Aceito em: 18.11.2016

Inf. Inf., Londrina, v. 21, n. 3, p. 185 - 206, set./dez., 2016. 